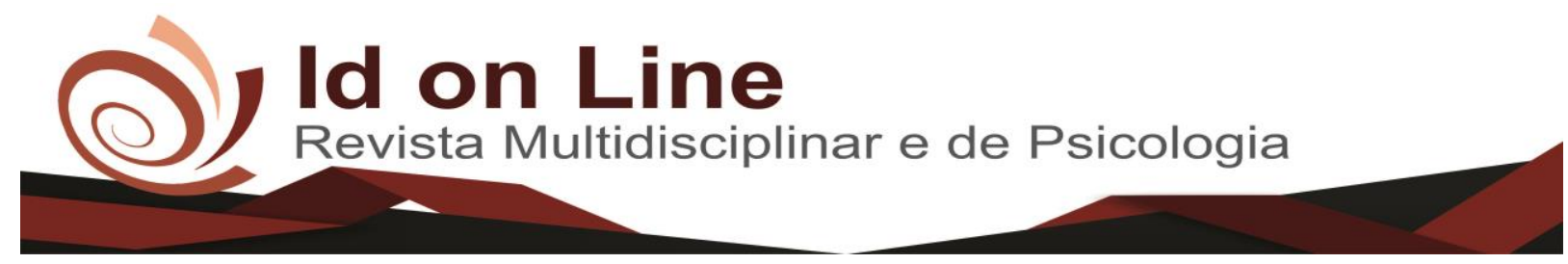

Artigo

\title{
Os Efeitos da Liderança Feminina na Administração Pública, no Tribunal de Contas de Alagoas
}

\author{
Rosa Maria Tavares Fragoso ${ }^{1}$
}

\begin{abstract}
Resumo: Se pretende em esta investigação estabelecer quais são os efeitos da liderança feminina na administração pública. É imperioso nesse contexto abordar acerca dessa realidade no âmbito público, o que será respaldado por dados elencados em relação às dificuldades encontradas pela mulher no seu ambiente de trabalho, a sua abordagem histórica para se ter direito ao trabalho, a sua posição como líder na Administração Pública, as condições de incentivo que lhe são propostas, bem como as atribuições do Tribunal de Contas. Dessa forma, compreendendo a relevância do tema em comento, pretende-se abordar os aspectos mais relevantes que o tema propõe, por meio de uma pesquisa bibliográfica, exploratória quali quantitativa ainda que sucintamente, a fim de explorar um assunto que atinge várias mulheres em várias categorias profissionais no cenário contemporâneo. A condição de trabalho, no âmbito do relacionamento dos homens em face às mulheres é ainda de superioridade, haja vista, a ótica tradicional cultural. A predominância masculina é ainda expressiva se comparada com a ênfase no trabalho feminino. Quando a pessoa que representa um líder acaba sendo perseguida por aqueles que não veem como tal, é importante que o líder crie um ambiente de apoio emocional, conforto, amizade e confiança. A valorização da mulher no espaço de trabalho vem percorrendo caminhos árduos e que hoje ainda de forma tímida precisam de maior ênfase; as estratégias das lideranças nas organizações devem ser compatíveis com os segmentos e perfis de mercado. O peso incumbido as várias atribuições que a mulher carrega, como profissional, mãe, esposa e filha causa muito desgaste físico, sobretudo, emocional. Um incentivo para as mulheres deve ser pautado na confiança, sendo, portanto, a base para as relações se tornarem sólida e para o alcance de resultados satisfatórios.
\end{abstract}

Palavras-chave: Liderança feminina. Desigualdade no trabalho. Tribunal de Contas.

\section{The Effects of Women's Leadership in Public Administration in Alagoas Court of Auditors}

\begin{abstract}
It is imperative in this context to address this reality in the public sphere, which will be supported by data on the difficulties encountered by women in their work environment, their historical approach to the right to work, their position as a leader in the Administration The proposed conditions of incentive and the tasks of the Court of Auditors. In this way, understanding the relevance of the theme in the commentary, we intend to approach the most relevant aspects that the theme proposes, through a bibliographic and exploratory research, although succinctly, in order to explore a subject that reaches several women in several categories Professionals in the contemporary scenario. The working condition, in the context of the relationship of men to women is still superior, given the traditional cultural view. In the year 2003 to 2010 the women fought for the equality and its varied matrices. Male dominance is still significant compared to the emphasis on female work. When the person representing a leader ends up being persecuted by those who do not see it as such, it is important for the leader to create an environment of emotional support, comfort, friendship, and trust. The valorization of women in the work space has been going through arduous paths and that today still in a timid way need greater emphasis; The strategies of the leaders in the organizations must be compatible with the segments and profiles of the market. The weight assigned to the various duties that the woman carries, as a professional, mother, wife and daughter causes a lot of physical, especially emotional, weariness. An incentive for women should be built on trust and thus the basis for relationships to become sound and to achieve satisfactory results.
\end{abstract}

Key-words: Female leadership. Inequality in work. Audit Office.

\footnotetext{
${ }^{1}$ Maestría en Gobierno y Gerencia Pública. Universidad Americana. Facultad de Posgrado. Asuncion - PY.
} 


\section{Introdução}

Por longos períodos, a desigualdade entre mulheres e homens foi uma realidade, haja vista a postura patriarcal e machista da sociedade, o que propiciou uma inserção tardia da mulher no mercado de trabalho e a busca para sua ascensão em nível de igualdade profissional com os homens, ainda que incipiente.

Desse modo, percebe-se que muitos são os questionamentos frente à realidade que permeia a vida pessoal de muitas mulheres, através de sua posição no ambiente laboral público. Isso reflete a necessidade de se promover maiores discussões em torno dessa temática, justificando assim sua abordagem sobre os pontos mais relevantes que a temática exposta propõe.

Os objetivos do presente estudo foram: a: Estabelecer quais são os efeitos da liderança feminina na Administração Pública no Tribunal de Contas do Estado de Alagoas; b) Precisar as atitudes dos colegas masculinos ante a participação da mulher na Administração Pública; c) Analisar as formas de lideranças e a capacidade de adaptação da mulher com um mundo cada vez mais globalizado; d) Reconhecer as dificuldades achadas para uma liderança eficaz; e) Identificar o comportamento dos parceiros respeito a trabalho desempenhado pelas mulheres que realizam tarefas na Corte de Alagoas; e, d) Apresentar os desafios e o planejamento incorporado no desenvolvimento econômico durante a gestão pública.

\section{A Participação da Mulher na Administração Pública}

Estudo do IBGE mostra que em 2014 as trabalhadoras mulheres receberam 80\% do salário dos colegas homens. Essa diferença, que havia sido de 25,3 \% em 2012 e de 25,8\% em 2013, passou a ser de $25 \%$ em 2014.

Na comparação dos números absolutos, de 2013 para 2014, houve aumento do número de mulheres $(2 \%)$ e recuo no número de homens $(-0,1 \%)$. Isso fez com que a proporção de homens no mercado de trabalho recuasse 0,5 ponto porcentual em 2014 e que a das mulheres aumentasse na mesma proporção. A administração pública e as entidades sem fins lucrativos apresentaram maior participação feminina entre seus trabalhadores. Em 2014, nas entidades empresariais predominava o profissional masculino, segundo o IBGE. O número de mulheres vem crescendo ano a ano. Nas empresas públicas, a entrada é facilitada pelos concursos, em que o mérito é que conta, mas a participação feminina também está crescendo nas empresas privadas, embora em menor número. 
Sob a ótica da natureza jurídica, a administração pública e as entidades sem fins lucrativos apresentaram maior participação feminina entre os funcionários. Em contrapartida, nas entidades empresariais, predominam os trabalhadores homens em todo o período considerado.

No âmbito das condições de trabalho, o relacionamento dos homens em relação às mulheres é ainda de superioridade, haja vista, a ótica tradicional cultural de que as mulheres são mais frágeis, são destinadas às atividades domésticas, o que reflete o posicionamento machista nas relações de trabalho.

\section{A Mulher como Líder na Administração Pública e o Acesso ao Cargo}

No cenário público, observa-se que sua evolução acompanhou o ritmo de mudanças de Estado e mudanças dos objetivos dos governos. Hoje, a Administração Pública se constitui em uma parte da ciência da Administração que se refere ao governo, e que encontra vinculada tanto a norma técnica, como a lei, sob forma hierarquizada.

Para Saldanha (2006, p.11), a Administração Pública no seu sentido funcional representa:

O conjunto das funções necessárias aos serviços públicos em geral, no que se refere ao sentido operacional é o desempenho perene e sistemático, legal e técnico dos serviços próprios do Estado ou por ele assumidos em um benefício da coletividade.

É importante enfatizar que a Administração Pública, o governo e gestão pública são considerados sinônimos, no entanto, representam vários aspectos e conceitos diversos.

Para Matias-Pereira (2007, p.10), a expressão Administração Pública, num sentido amplo consiste em:

Todo o sistema de governo, todo o conjunto de ideias, atitudes, normas, processos, instituições e outras formas de conduta humana, que determinam. (a) como se distribui e se exerce a autoridade política; (b) como se atendem aos interesses públicos. Assim, a Administração Pública pode ser entendida como a estrutura do Poder Executivo, que tem a missão de coordenar e implementar as políticas públicas. Apresenta-se como um conjunto de atividades diretamente destinadas à execução concreta das tarefas consideradas de "interesse público" ou comum numa coletividade ou numa organização estatal.

No que tange à Administração Pública Amato apud Saldanha (2006, p. 12) ressalta: "é a gestão dos bens e interesses qualificados da comunidade, nos âmbitos federal, estadual ou municipal, segundo o preceito do direito e da moral, visando o bem comum". 
Logo, observa-se que os bens e interesses são geridos sobre natureza individual e se desenvolve uma administração particular e caso os bens e interesses sejam coletivos, ocorre a Administração Pública.

Para Lima (2005), a história da reforma administrativa no setor público brasileiro tem início nos anos 30 e somente na metade do século XX, há o início da era da informação e do conhecimento, caracterizada por um período de grandes transformações tecnológicas, sociais e econômicas, que impõem novos padrões de gestão às organizações públicas e privadas.

O processo de reforma trata-se de uma reestruturação produtiva apoiada no desenvolvimento científico e tecnológico e na globalização de mercados. Para Castor; José (1998), as diversas experiências de reforma administrativa representam um embate entre dois sistemas: a burocracia e processos inovadores.

No processo de burocracia, em seu sentido corporativo, centralizador, bloqueia as mudanças de cunho organizacional e nas formas de operar do aparelho estatal.

Quanto aos processos inovadores, essas forças propulsoras, não raramente, encontram muitas dificuldades para implementar projetos de reforma de maneira efetiva. Logo, trata-se de uma visão simplificada da realidade, posto que sugira uma espécie de embate entre o bem e o mal (LIMA, 2005). $\mathrm{Na}$ verdade, qualquer processo de mudança favorece certos interesses à custa de outros. Portanto, convém analisar tais processos à luz do contexto social, histórico, como também cultural no qual se inserem.

Por meio da reforma do Aparelho do Estado na década de 90, a Administração Pública procurou desenvolver uma nova gestão, com a finalidade de promover a defesa do patrimônio público, logo, sua evolução promoveu o desenvolvimento de três modelos de gestão, a saber: Patrimonialista; Burocrática e, Gerencial.

No que concerne ao modelo patrimonialista, o aparelho do Estado é desenvolvido como uma ferramenta que dispõe de bens públicos para a utilização da melhor forma possível, para seu benefício, como também para os colaboradores. Logo, esse tipo de modelo promove por sua vez o nepotismo, a improbidade administrativa e a corrupção, uma vez que está vinculada a soberania nas mãos de poucos.

Quanto à Administração Pública Burocrática, esta foi desenvolvida em meados do século XIX, a qual esteve voltada a adoção de controles rígidos para combater atos de corrupção dentre outros.

No tocante ao terceiro e último modelo de Administração, observou-se o surgimento da Administração Pública gerencial que conduz a uma nova postura, passando a ser orientada pela eficiência e a qualidade na execução dos serviços públicos.

No contexto da atualidade, a Administração Pública representa um conjunto de serviços, órgãos e agentes de Estado, que por sua vez, tendem a satisfazer as necessidades de cunho social, ou 
seja, representam uma gestão para se atingir interesses públicos, através da administração direta e indireta.

Para Seresuela (2002), a administração direta é caracterizada pelo seu exercício concentrado pelos órgãos internos, enquanto a indireta é realizada por atividades estatal, como exemplo: fundação, autarquia, empresa pública etc. Outro ponto relevante faz menção aos órgãos públicos, que por sua vez fazem parte da estrutura do Estado, como também das outras pessoas jurídicas para que se exerçam as finalidades institucionais.

Vale ressaltar que, alguns fatores foram decisivos para movimentos de reforma e de mudança no aparelho do Estado para se tornar cada vez mais eficiente, ágil e flexível. Logo, no setor público o grande desafio foi de transformar a administração pública com estruturas burocráticas, hierarquizadas e culturas centralizadoras para organizações mais flexíveis e que correspondessem aos anseios de seu corpo organizacional, bem como de interesse social.

Desta feita, após romper as formas de administração pública patrimonialista e burocrática, hoje a administração pública se apresenta permeável a maior participação dos agentes privados e ou das organizações da sociedade civil, graças a sua capacidade de flexibilidade e de seus princípios fundamentais.

Para Lima (2009), as tentativas de reforma na administração pública visam uma maior eficiência e qualidade na prestação de serviços públicos, o que requer a substituição das formas arcaicas e tradicionais e introduzir uma nova cultura de gestão.

As atividades na Administração Pública exigem que a organização dos quadros de pessoal esteja adequada às necessidades de gestão, e, portanto, podem ser flexíveis para se adaptar as transformações do órgão.

Nessa linha de análise, pressupõe-se que administração é uma atividade neutra, porém vinculada a lei ou a norma técnica. No que se refere a sua importância, a Administração Pública atua em defesa do interesse público, o que exige contínua postura de fiscalização, bem como de conciliar plenamente os princípios de legalidade, impessoalidade, legitimidade, especialidade, controle, eficiência, segurança, motivação, dentre outros.

Nesse contexto é oportuno ressaltar que sua aplicabilidade está voltada as aspirações sociais, ou seja, ao bem comum, como também aos preceitos político-administrativos tendo como consideração os ditames administrativos e processuais.

Logo, a Administração Pública é destinada aos demais atos administrativos com interesse da coletividade. Logo é importante que se estabeleça transparência em toda a sua tramitação e controle sobre a condução de seus interesses. 
Dessa forma, sua relevância é ratificada pela prevalência e supremacia do interesse público sobre o privado, ou seja, o interesse coletivo deve sempre ser superior aos interesses de cunho pessoal ou particular (MELLO, 1997).

Sendo assim, é através da descentralização e do grau de autonomia de órgãos e instâncias da administração, é que a Administração Pública vem garantindo seu fortalecimento democrático, bem como em propor a continuidade de aperfeiçoamentos para o seu principal foco de execução, o interesse público.

Com relação ao século $\mathrm{XX}$ surge a Administração Pública gerencial que substituiu a Administração Pública burocrática. Essa nova forma de administração é voltada para resultados dos anseios sociais e sua atribuição é delegar autoridade, ou seja, ela é descentralizada e busca a eficiência.

Nesse contexto, observa-se que no cenário atual a Administração Pública é aplicada dentro de uma perspectiva democrática, inclusive com a participatividade da sociedade por meio de audiência pública, representando assim um instrumento de controle e participação popular.

No tocante a sua forma de classificação, é formada pela Administração direta ou centralizada e indireta ou descentralizada.

Assim, na Administração Direta, Grangeiro (2002) dispõe que é formada pela parte administrativa da Presidência da República, bem como dos Ministérios.

Com relação à Administração Indireta, caracteriza-se como a gestão dos serviços públicos por qualquer tipo de entidade pública ou privada desde que diversa da pessoa jurídica pública política de existência necessária.

Segundo Takeda (2009), a Administração Pública Indireta representa o conjunto formado por órgãos públicos que fazem parte de forma indireta do chefe da esfera governamental. Assim, apresentam personalidade jurídica própria, dotado de autonomia administrativa e as despesas também são efetuados por orçamentos próprios.

Discorrendo-se da Administração Indireta ou descentralizada, Alves (2008) enfatiza a repartição de funções no âmbito interno do próprio órgão ou entidade carregada de executar um ou mais serviços. Assim, não há quebra de hierarquia, apenas a distribuição de competências específicas que serão repassadas dentro de uma única pessoa jurídica.

Assim sendo, observa-se que a diferença estabelecida entre a Administração Pública Direta e Indireta se concentra na centralização e descentralização de administrativo, bem como pela composição de entidades, o que se constitui de suma importância para a prestação de serviços públicos que visam o interesse público.

De forma abrangente, a Administração Pública é formada por interesses e motivos diversos. No entanto, é dirigida para atender as necessidades da população. Dessa forma, os seus dirigentes devem 
desenvolver projetos, superar obstáculos, controlar seu ambiente, por meio de tarefas e coordenação de esforços visando sempre atingir o bem comum através de funções, papéis, órgãos ou setores.

Para muitos autores, a Administração Pública se constitui na gerência, na organização de recursos humanos e materiais, a fim de atingir propostas de um governo. No que se refere à gestão pública relaciona-se com as funções da gerência pública do governo, ou seja, faz menção a uma fase de mandado, o que implica em validade por um tempo determinado.

A finalidade da gestão pública é alcançar o bem comum da coletividade administrada e a sua natureza é a de um encargo de defesa, conservação e aprimoramento dos bens para o interesse comum.

Perante essa linha de conduta, na gestão pública, há princípios calcados no art. 37 da Carta Magna, que podem ser classificados como: legalidade, impessoalidade, moralidade e publicidade, finalidade, continuidade, indisponibilidade e igualdade.

Sob a perspectiva de Mello (2013, p. 12), o Princípio da Igualdade interdita tratamento:

Desuniforme às pessoas. Sem embargo, pode-se observar, a função precípua da lei, que significa exatamente dispensar tratamentos desiguais, ou seja, as normas legais nada mais fazem que discriminar situações, de forma que as pessoas compreendias em uma ou em outra vêm a ser colhidas por regimes diferentes. De onde, a alguma são deferidos determinados direitos e obrigações que não assistem a outras, por abrigadas em diversa categoria, reguladas por diferente plexo de obrigações e direitos inerentes a sociedade brasileira.

A igualdade deve ser objeto de direito de todo o cidadão, haja vista, se tratar de um princípio que destinado a dirimir barreiras da desigualdade e acima de tudo está preconizada na Carta Magna.

Conforme reza Pinho (2002, p. 95), o fundamento do direito de Igualdade encontra-se:

No princípio de que todos devem ser tratados de forma igual perante a lei. Todos nascem e vivem com os mesmos direitos e obrigações perante o Estado. A igualdade foi um dos ideais da Revolução Francesa atingidos com a abolição dos antigos privilégios da nobreza e do clero. Todos passaram a ter o mesmo tratamento perante a lei.

A Isonomia de que trata a Constituição da República de 1988, traz dois aspectos substanciais a igualdade: Formal e Material. Quando se fala da igualdade formal remete-se àquela caracterizada pelo Estado Liberal, onde todos são iguais perante a lei na sua forma absoluta, pois a esta não existe nenhuma diferença. Mas quando se refere à isonomia material, pode-se analisar que se busca uma igualdade plena em todos os setores que regulam o convívio e sociedade, sendo esta a mais adequada a servir de instrumento para promover a igualdade e a justiça social a todos os cidadãos.

Desse modo, não se pode olvidar que a igualdade como princípio constitucional ainda está muito distante de sua prática, visto que, ainda é predominante a desigualdade entre homens e mulher em cargos de alto nível hierárquico. 
Segundo preceitua Farah (2001), ainda é predominante as desigualdades entre homens e mulheres nos cargos de chefia, visto que, por longos anos a visão da mulher sempre ficou atrelada as cuidados domésticos. Logo, em órgãos onde a maioria dos cargos é predominante por homens, convém discorrer acerca dos Tribunais de Contas.

O Tribunal de Contas da União caracteriza-se em órgão colegiado e suas deliberações são tomadas no Plenário em suas duas câmaras, podendo ocorrer, esporadicamente decisões por despacho singular, nos casos previstos no regimento interno.

Para Peixe (2006, p. 141): "o sistema de Tribunais de Contas do Brasil, lutam pela batalha da moralidade na avaliação dos dinheiros e na racional utilização dos bens e valores públicos, resistindo à prática de abusos e ilegalidades."

No tocante à origem dos Tribunais de Contas a nível mundial, alguns foram organizados como evolução do controle interno, como é o caso da modelo alemão, e os criados pelo poder legislativo para auxiliar no controle externo, como o modelo inglês.

Já em relação ao Brasil, Tribunal de Contas da União foi criado por Rui Barbosa, o ilustre mestre que considerava a sua criação o coroamento da obra do Governo Provisório na Primeira República.

Segundo preceitua Medauar (2003, p. 421), a criação do Tribunal de Contas deve-se:

\begin{abstract}
A iniciativa de Ruy Barbosa, em 1890, onde o Tribunal de Contas representa uma instituição estatal independente, pois seus integrantes têm as mesmas garantias atribuídas ao Poder Judiciário $\left(\mathrm{CF}\right.$, art. $\left.73, \S^{\circ}\right)$. Daí ser impossível considerá-lo subordinado ou inserido na estrutura do Legislativo. Se a sua função é atuar em auxílio ao Legislativo, sua natureza, em razão das próprias normas constitucionais, é a de órgão independente, desvinculado da estrutura de qualquer dos três poderes.
\end{abstract}

De forma geral, as discussões em torno da criação do Tribunal de Contas perduraram quase um século, sendo polarizadas entre aqueles que defendiam a sua necessidade, para quem as contas públicas deviam ser examinadas por um órgão independente, e aqueles que o combatiam, por aqueles mesmos que as realizavam.

Para Speck (2001) foi a partir da queda do Império que as reformas político-administrativas da jovem República tornaram realidade a instituição do Tribunal de Contas da União. Em sete de novembro de 1890, por iniciativa do então Ministro da Fazenda, Rui Barbosa, o Decreto n ${ }^{\circ}$ 966-A criou o Tribunal de Contas da União, norteado pelos princípios da autonomia, fiscalização, julgamento, vigilância e energia.

Com a implantação do Tribunal de Contas da União foi notória a competência de suas atribuições quanto ao exame, revisão e julgamento de todas as operações relacionadas com a receita e a despesa da União. O mecanismo de fiscalização se fazia pelo sistema de registro prévio e a Constituição 
de 1891, que institucionalizou o Tribunal, conferiu-lhe a competência para liquidar as contas da receita e despesa e verificar a sua legalidade antes de serem apresentadas as contas ao Congresso Nacional.

Após a instalação deste Tribunal, as Cortes de Contas começaram, aos poucos, a ser implantadas nos Estados da Federação. Consta que os Tribunais mais antigos são os dos Estados do Piauí, instalado em 1899, e da Bahia. Este, instituído em 1915, é originário do Tribunal de Conflitos e Administrativo criado pela Constituição Baiana de 1891.

No ano de 1923, surge o Tribunal de Contas do Estado de São Paulo. No ano de 1935, criaramse os Tribunais de Contas dos Estados de Minas Gerais, Rio Grande do Sul e Ceará. Na década seguinte, surgiram os Tribunais estaduais do Maranhão, Mato Grosso, Santa Catarina, Paraná, Goiás, Alagoas e Pará.

Com relação ao Tribunal de Contas do antigo Estado do Rio de Janeiro foi criado em 1947 e extinto em 1975 devido à fusão desse Estado com o da Guanabara. Nesse mesmo ano, criou-se o atual Tribunal de Contas estadual. Nos anos 50, nascem os Tribunais de Contas do Estado do Amazonas e Espírito Santo e o Conselho de Assistência Técnica dos Municípios do Estado do Ceará, transformado em Conselho de Contas dos Municípios, e, mais tarde, em Tribunal de Contas dos Municípios.

Somente a partir da década de 60, surgem os Tribunais de Contas do Distrito Federal, dos Estados de Pernambuco e Rio Grande do Norte e, ainda, o Tribunal de Contas do Município de São Paulo. Em 1970, é a vez de serem criados os Tribunais dos Estados de Paraíba e de Sergipe e dos Municípios da Bahia. Em 1976, nasce o Tribunal de Contas do Município do Rio de Janeiro e, no ano seguinte, o Tribunal de Contas dos Municípios do Estado de Goiás (SOUZA, 2004).

Antes da promulgação da atual Constituição, surgem, na década de 80, os Tribunais dos Estados de Mato Grosso do Sul, Rondônia e Acre, bem como o Tribunal de Contas dos Municípios do Estado do Pará. Posteriormente, cria-se o Tribunal de Contas dos Estados de Tocantins, Amapá e Roraima. É interessante notar que as Cortes de Contas estaduais e municipais foram criadas, ora por meio das Constituições estaduais, ora por via de leis complementares, leis ordinárias, decretos e decretos-lei. Entretanto todas elas foram regulamentadas, posteriormente, por Leis Orgânicas, sejam elas leis complementares ou ordinárias. (IBIDEM, 2005)

Logo após sua instalação, porém, o Tribunal de Contas considerou ilegal a nomeação, feita pelo Presidente Floriano Peixoto, de um parente do ex-presidente Deodoro da Fonseca. Inconformado com a decisão do Tribunal, Floriano Peixoto mandou redigir decretos que retiraram do TCU a competência para impugnar despesas consideradas ilegais. O Ministro da Fazenda, Serzedello Corrêa, não concordando com a posição do Presidente, demitiu-se do cargo.

Pela Constituição de 1934, o Tribunal recebeu, entre outras atribuições, a de proceder ao acompanhamento da execução orçamentária, o registro prévio das despesas e dos contratos, o julgamento das contas dos responsáveis por bens e dinheiro públicos, assim como a apresentação de 
parecer prévio sobre as contas do Presidente da República para posterior encaminhamento à Câmara dos Deputados.

Com exceção do parecer prévio sobre as contas presidenciais, todas as demais atribuições do Tribunal foram mantidas pela Carta de 1937. Foi a Constituição de 1946 que acresceu sua competência com um novo encargo: julgar a legalidade das concessões de aposentadorias, reformas e pensões (JUND, 2008).

Desta feita, o processo de fiscalização financeira e orçamentária passou por completa reforma. Como inovação, deu-se incumbência ao Tribunal para o exercício de auditoria financeira e orçamentária sobre as contas das unidades dos três Poderes da União, instituindo-se, desde então, o sistema de controle externo, a cargo do Congresso Nacional, com auxílio da Corte de Contas, e de controle interno, este exercido pelo Poder Executivo e destinado a criar condições para um controle externo eficaz.

De forma geral, as discussões em torno da criação do Tribunal de Contas perduraram quase um século, sendo polarizadas entre aqueles que defendiam a sua necessidade, para quem as contas públicas deviam ser examinadas por um órgão independente, e aqueles que o combatiam, por aqueles mesmos que as realizavam.

Segundo Castro (2009, p. 44):

Na época enquanto Ministro da Fazenda, Rui Barbosa motivou o Decreto n 996/A, de 7 de novembro de 1890, o qual delineou os marcos e papéis da nova instituição ao consignar que o Tribunal de Contas seria o corpo de magistratura intermediária à administração e à legislatura que, colocado em posição autônoma, com atribuições de revisão e julgamentos, cercado de garantias contra quaisquer ameaças, pudesse exercer as suas funções vitais no organismo constitucional, sem risco de converter-se em Instituição de formato aparatoso e inútil.

No que tange aos governantes, portanto, são considerados como gestores de bens alheios. Dessa forma, torna-se significativo a existência de um órgão que possa controlar a conduta administrativa desgarrada dessa função que lhe cabe e que possa ainda defender a administração contra o próprio administrador. Logo, o tribunal de Contas cumpre esse papel (FIGUEIREDO; NÓBREGA, 2002).

Embora apontado como órgão auxiliar do Poder Legislativo, o Tribunal de Contas não faz parte de esse poder. De outra parte, como é evidente, menos ainda se encaixa no Poder Executivo, tanto mais porque dificilmente se pode imaginar que o controlador seja uma dependência do controlado. Também não é órgão que faça parte do Poder Judiciário. Portanto, o Tribunal de Contas, no sistema brasileiro é um conjunto orgânico autônomo.

Discorrendo-se do seu trabalho de auxílio com o Legislativo como órgãos técnicos em seu parecer prévio são observáveis os seguintes aspectos segundo Peixe (2006):

- $\quad$ A apreciação das contas do titular do poder executivo;

- $\quad$ O desempenho das funções de auditoria financeira e orçamentária; 
- O julgamento das contas dos administradores e demais responsáveis por bens e valores públicos.

Logo, constata-se que o Tribunal de Contas dará parecer prévio sobre as contas que o titular do Poder Executivo prestará anualmente, e no caso de não encaminhamento, o fato será comunicado ao Poder Legislativo, devendo o Tribunal apresentar minucioso relatório sobre o exercício encerrado.

No desempenho de suas atribuições o tribunal recebe periodicamente uma parte da documentação contábil e outros demonstrativos relativos à atuação das unidades sujeitas a sua jurisdição, que são apreciados sob a forma de tomadas e prestações de contas. Essas contas são analisadas sob os aspectos de legalidade, impessoalidade, moralidade e publicidade e eficiência (Princípios Constitucionais da Administração Pública), e depois são julgadas regulares, regulares com ressalvas, irregulares ou iliquidáveis.

Para o controle externo, sua administração é independente e realizada por órgão autônomo e baseada em ações de fiscalização. Logo, os Tribunais de Contas atuam nesse segmento, analisando fatos contábeis, patrimoniais e financeiro-orçamentárias (TAKEDA, 2009).

As contas são julgadas regulares quando a prestação de contas expressa de forma clara e objetiva a exatidão dos demonstrativos contábeis, a legitimidade e a economicidade dos atos de gestão do responsável. As regulares com ressalvas decorrem da existência de impropriedades ou falta de natureza formal de que não resultem danos ao erário.

No caso das contas serem julgadas irregulares advém da omissão no dever e prestá-las, da prática de ato de gestão ilegal, ilegítimo, antieconômico, ou infração a norma legal ou regulamentar de natureza contábil, financeira, orçamentária, operacional ou patrimonial, de dano ao erário decorrente de ato de gestão ilegítimo ou antieconômico, de desfalque ou desvio de dinheiros, bens ou valores públicos e de reincidência no descumprimento de terminações do Tribunal. São julgadas iliquidáveis as contas que apresentarem materialmente impossíveis de julgamento de mérito.

Segundo Figueiredo; Nóbrega (2002), o controle exercido por meio de tomadas e prestações de contas, é considerado como a título de posteriori. Desta feita, o Tribunal atua com funções voltadas a inspeções e auditorias, tanto de forma rotineira quanto de caráter específico e ocasional, visando atingir maior eficiência e eficácia em sua atuação, procedendo sempre de acordo com sistemáticas constantes de seus manuais internos.

Nesse limiar, é importante enfatizar que nenhum processo, documento ou informação pode ser sonegado sob qualquer pretexto, podendo o Tribunal até mesmo determinar cautelarmente o afastamento provisório dos dirigentes que criarem dificuldades ou retardarem os trabalhos.

À corte e a seus Ministros é facultado, a realização de diligências que objetivem o esclarecimento de dúvidas surgidas no decorrer de suas análises. Essas diligências são de atendimento obrigatório no prazo fixo, geralmente de 15 dias, sujeitam ao gestor que não as observar a aplicação de 
multa. O julgamento dos processos e imposição de sanções que não são feitas arbitrariamente, sendo concedido aos responsáveis o direito a ampla defesa. Assim, o tribunal, diante de irregularidades detectadas em suas análises, determina, sempre, a audiência prévia ou a citação dos interessados, que não estão atendendo e que serão julgados à revelia (LIMA, 2009).

Para Matias-Pereira (2006), os Tribunais de Contas têm-se afirmado como importantes instituições para o desenvolvimento do país, com o esforço de tornar transparentes as finanças públicas, definir responsabilidades e avaliar o impacto das ações governamentais para a melhoria das condições de vida da comunidade.

Conforme Mukai (1999), os Tribunais de Contas são auxiliadores do Poder Legislativo segundo o art. 71, I a VIII da Constituição Federal, cujas atribuições visam apreciar as contas públicas, enfatizando a necessidade da legalidade, auditoria e fiscalização na prestação das contas públicas.

Segundo Granjeiro (2002), os Tribunais de Contas possuem a função de realizar inspeções e relatórios sobre o exercício encerrado sobre as contas do titular do Poder Executivo que prestará anualmente seus demonstrativos financeiros.

O Tribunal de Contas da União tem suas competências previstas nos arts. 33, $2^{\circ}, 71$ a 74 e 161, parágrafo único, da Constituição Federal de 1988. Além disso, em razão do exercício das competências constitucionais outras incumbências foram-lhe atribuídas por lei. Logo, para um maior aprofundamento das competências constitucionais e legais do TCU são as ressaltadas as que seguem, conforme quadro abaixo:

Quadro 2- Competências constitucionais do Tribunal de Contas da União

\begin{tabular}{|l|l|}
\hline \multicolumn{1}{|c|}{ Competências Constitucionais } & \multicolumn{1}{|c|}{ Fundamento } \\
\hline Apreciar as contas anuais do Presidente da República & Art. 71, I \\
\hline $\begin{array}{l}\text { Julgar as contas dos administradores e demais } \\
\text { responsáveis por dinheiros, bens e valores públicos }\end{array}$ & Art. 33, §2 e art. 71, II \\
\hline $\begin{array}{l}\text { Apreciar a legalidade dos atos de admissão de pessoal e } \\
\text { de concessões de aposentadorias, reformas e pensões } \\
\text { civis e militares }\end{array}$ & Art. 71, III \\
\hline $\begin{array}{l}\text { Realizar inspeções e auditorias por iniciativa própria ou } \\
\text { por solicitação do Congresso Nacional }\end{array}$ & Art. 71, IV \\
\hline $\begin{array}{l}\text { Fiscalizar as contas nacionais das empresas } \\
\text { supranacionais }\end{array}$ & ARt. 71, V \\
\hline $\begin{array}{l}\text { Fiscalizar a aplicação de recursos da União repassados a } \\
\text { Estados, ao Distrito Federal ou a Municípios }\end{array}$ & Art. 71, VI \\
\hline $\begin{array}{l}\text { Prestar informações ao Congresso Nacional sobre } \\
\text { fiscalizações realizadas }\end{array}$ & Art. 71, VII \\
\hline $\begin{array}{l}\text { Aplicar sanções e determinar a correção de ilegalidades e } \\
\text { irregularidades em atos e contratos }\end{array}$ & Art. 71, VIII a XI \\
\hline $\begin{array}{l}\text { Fiscalizar as aplicações de subvenções e a renúncia de } \\
\text { receitas }\end{array}$ & Art. 70 \\
\hline
\end{tabular}




\begin{tabular}{|l|l|}
\hline $\begin{array}{l}\text { Fiscalizar pronunciamento conclusivo, por solicitação da } \\
\text { Comissão Mista Permanente de Senadores e Deputados, } \\
\text { sobre despesas não autorizadas }\end{array}$ & Art. $72, \S 1^{\circ}$ \\
\hline $\begin{array}{l}\text { Apurar denúncias apresentadas por qualquer cidadão, } \\
\text { partido político, associação ou sindicato sobre } \\
\text { irregularidades ou ilegalidades }\end{array}$ & Art. $74, \S 2^{\circ}$ \\
\hline $\begin{array}{l}\text { Fixar os coeficientes dos fundos de participação dos } \\
\text { Estados, do Distrito Federal e dos Municípios e fiscalizar } \\
\text { a entrega dos recursos aos governos estaduais e ás } \\
\text { prefeituras }\end{array}$ & Art. 161, parágrafo único \\
\hline
\end{tabular}

Fonte: Lima (2009, p. 80).

Logo, é importante que essas inspeções sejam baseadas em levantamentos contábeis, certificados de auditoria e pronunciamento das autoridades administrativas, para que possa se realizar um julgamento com o rigor da moralidade através da apuração dos fatos e dos representantes legais das contas da administração pública. Para Lima (2009), a função sancionadora do Tribunal de Contas da União configura-se na aplicação aos responsáveis, em caso de ilegalidade de despesa ou irregularidade de contas, das seguintes sanções, isolada ou cumulativamente:

- Reconhecimento do débito eventualmente apurado;

- Aplicação de multa ao agente público proporcional ao valor de prejuízo causado ao erário; o montante do dano é o limite máximo da penalidade;

- Aplicação de multa ao responsável por contas julgadas irregulares, por ato irregular, ilegítimo ou antieconômico, por não-atendimento de diligência ou determinação do Tribunal, por obstrução ao livre exercício de inspeções ou auditorias e por sonegação de processo, documento ou informação;

- Afastamento provisório do dirigente responsável por cerceamentos a inspeções e auditorias enquanto durarem os respectivos trabalhos;

- Decretação no curso de qualquer apuração de irregularidade, da indisponibilidade, por prazo não superior a um ano, dos bens do responsável para garantir o ressarcimento do prejuízo;

- Declaração de inabilitação, pelo período de cinco a oito anos, para o exercício de cargo em comissão ou função de confiança no âmbito da administração pública;

- Declaração de inidoneidade do responsável por fraude em licitação para participar, por até cinco anos, de certames licitatórios promovidos pela administração pública;

Vale ressaltar que ao Tribunal de Contas, cabe a aplicação de auditorias financeiras, como de outra natureza. Sua contribuição visa à melhoria da Administração Pública, através da emissão de pareceres, os quais solicitam do Governo, medidas cabíveis para a melhoria dos projetos em matéria financeira. 
De acordo com Velloso (2011), os Tribunais de Contas, enquanto órgãos de controle externo se constituem de fundamental importância para a fiscalização dos gastos públicos, visto que, dificultam determinadas práticas administrativas executadas pela União.

Caracterizados como órgãos de grande tradição no setor público, os Tribunais de Contas atuam como auxiliares do Poder Legislativo. Dentre suas principais competências, observa-se o art. 71 da Constituição Federal, tais como: fixação de valores no que tange a distribuição de receitas de tributos para o Estado como também para o Município; pareceres das contas relativas aos gastos do Presidente da República e desenvolvimento de relatórios fiscais.

No Brasil, há o Tribunal de Contas (TCU), 27 tribunais de contas dos estados, incluindo o Tribunal de Contas do Distrito Federal e 6 dos municípios, mais os tribunais de contas específicos para as cidades do Rio de Janeiro e São Paulo.

As cortes de contas são compostas por ministros ou conselheiros, procuradores e técnicos, na qual os primeiros competem discutir e julgar os assuntos sujeitos ao controle externo; aos segundos cabem defender a ordem jurídica; e aos técnicos compete instruir os processos de tomadas e prestações de contas, bem como elaborar os relatórios de auditoria, para posterior julgamento.

Nos órgãos em questão constam também da seção que trata da fiscalização contábil, financeira e orçamentária do Poder Legislativo tanto na Constituição Federal de 1988, como das constituições estaduais e do Distrito Federal. A Constituição Federal, em particular, ampliou as funções desempenhadas pelas cortes de contas, acrescentando os critérios de legitimidade, economicidade e razoabilidade aos de legalidade e regularidade.

\section{Marco Metodológico}

Trata-se de um estudo exploratório, bibliográfico, documental, quali quantitativa tendo como proposta de trabalho averiguar através de uma revisão bibliográfica e uma observação in situ a liderança da mulher no âmbito público, ou seja, no Tribunal de Contas de Alagoas.

A população é composta por 1.911 funcionários efetivos e comissionados no Tribunal de Contas: no que tange as de mulheres que trabalham 78 funcionárias.

A amostra foi direcionada a uma população de 78 mulheres efetivas, com um questionário composto por perguntas fechadas e uma observação estruturada sobre quatro itens importantes que norteia a pesquisa.

\section{Análise dos Resultados}


Através das informações levantadas no Tribunal de Contas do Estado de Alagoas, procurou-se explicitar a realidade situacional de seus colaboradores em relação à liderança feminina, por meio de informações in loco, com base nos questionários destinados à população amostral de 78 funcionários. Com a aplicação dos questionários aos colaboradores, observaram-se os seguintes dados, a saber:

Quadro 3 - Questionário proposto aos funcionários do TC/AL

\begin{tabular}{|c|c|c|c|}
\cline { 2 - 4 } & $\begin{array}{c}\text { Como você percebe as } \\
\text { atitudes dos colegas } \\
\text { masculinos ante a } \\
\text { participação da mulher na } \\
\text { administração pública }\end{array}$ & $\begin{array}{c}\text { Segundo sua percepção, quais } \\
\text { as características e as atitudes } \\
\text { marcantes da mulher como } \\
\text { líder na administração pública }\end{array}$ & $\begin{array}{c}\text { Segundo seu critério, quais } \\
\text { as condições que devem ser } \\
\text { incentivadas para que a } \\
\text { mulher venha ganhar mais } \\
\text { espaço de poder }\end{array}$ \\
\hline BOA & 60 & 71 & 60 \\
\hline INDEFERENTE & 12 & 7 & 12 \\
\hline NÃO PERCEBE & 4 & 0 & 3 \\
\hline TOTAL & 2 & 0 & 3 \\
\hline
\end{tabular}

Com relação a Atitude dos colegas masculinos frente à participação da mulher na Administração Pública, Observe-se o gráfico a seguir:

Gráfico 1 - Atitude dos colegas masculinos frente à participação da mulher na Administração Pública

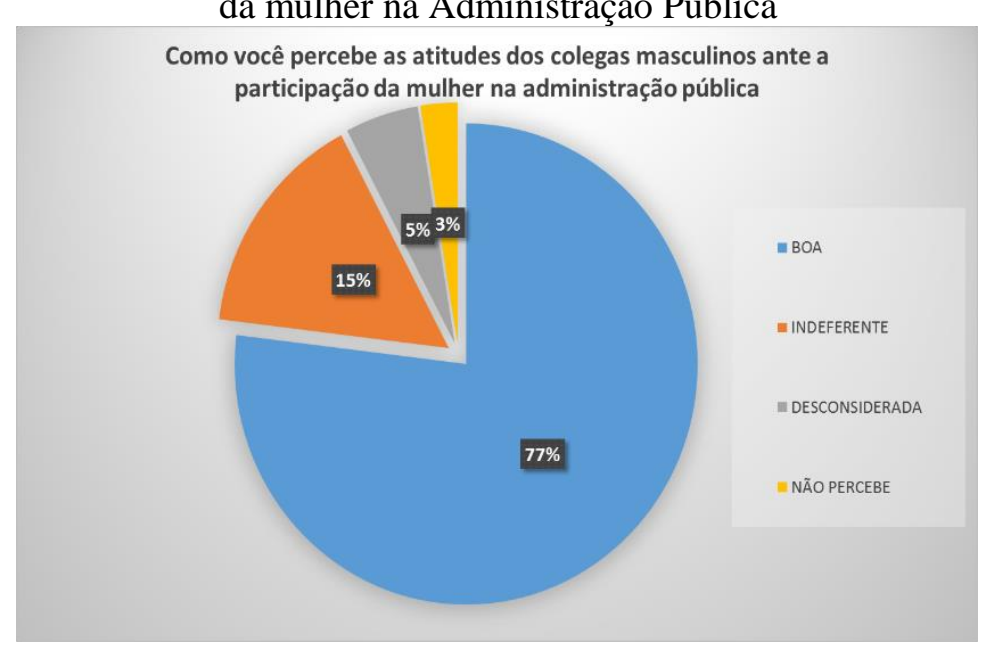

No gráfico acima citado, percebe-se que a atitude dos colegas masculinos frente à prática da mulher na Administração Pública é considerada como boa por $77 \%$ dos entrevistados. Da população amostral, $15 \%$ considera essa atitude como indiferente, $5 \%$ desconsidera e $3 \%$ não percebem. Assim, a 
relação dos colegas masculinos em sua maioria é considerada como harmônica favorável para o desempenho das atividades no âmbito de trabalho.

Gráfico 2 - Características marcantes da mulher como líder na Administração Pública

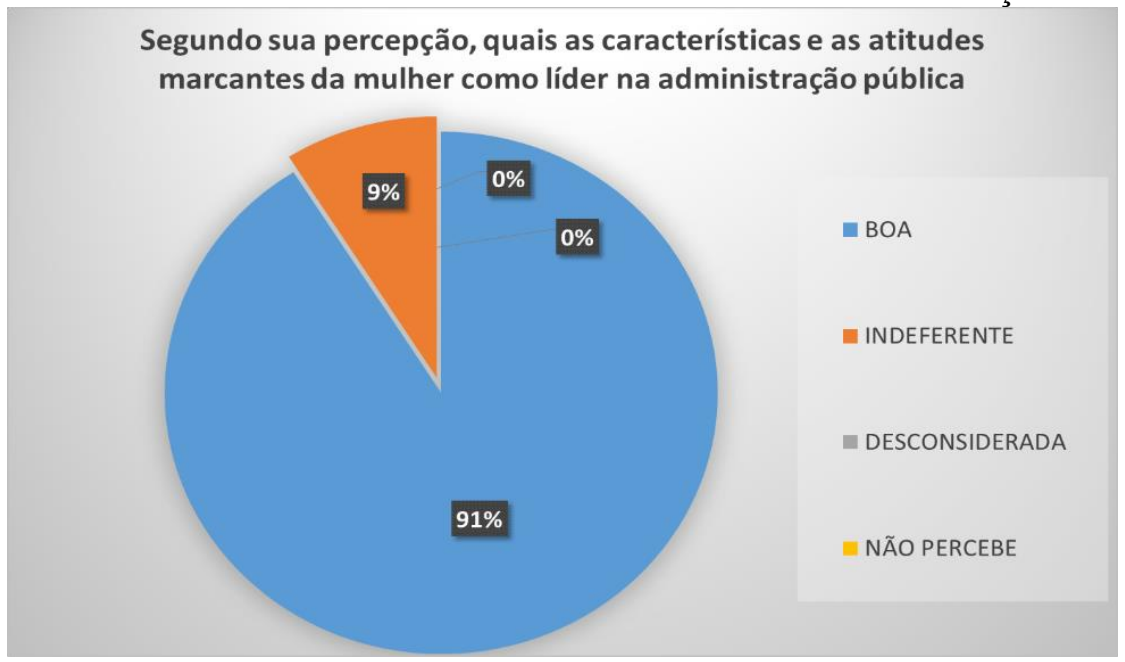

No que tange às informações supracitadas, as atividades que mais sobressaem da liderança feminina são consideradas como favoráveis por $91 \%$ dos entrevistados e $9 \%$ consideram como indiferente. Evidenciasse nas atitudes da liderança feminina que são consideradas positivas na Administração Pública.

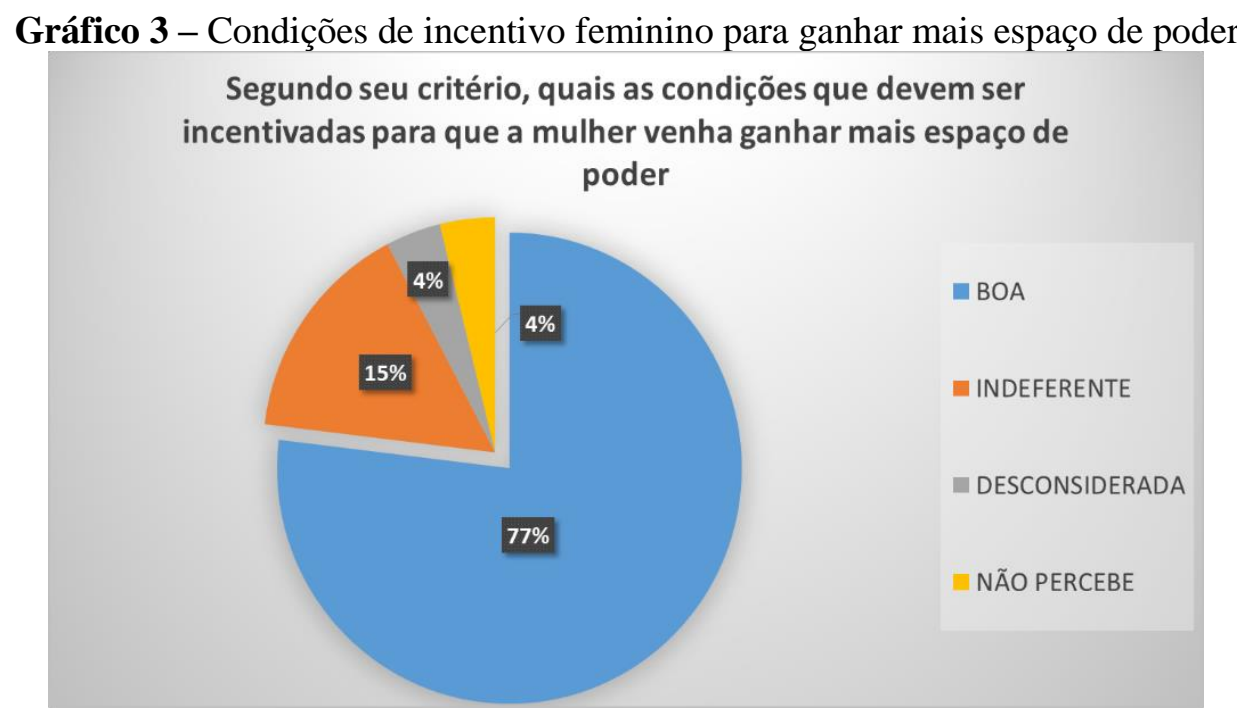

Por fim, concernente às condições para melhor incentivo feminino a fim de ganhar mais espaço de poder como líder, $77 \%$ dos entrevistados consideram que devem ser boas nas suas tarefas , 15\% 
consideram que devem ser indiferentes aos comentários negativos a cerca dela e $4 \%$ optam que desconsiderem e não percebem essa necessidade de apoio.

\section{Conclusões}

Com os apontamentos aqui propostos observou-se que a mulher para galgar direitos igualitários ao homem em relação ao trabalho passou por muitas dificuldades. Todavia, no cenário contemporâneo também não será uma das tarefas mais fáceis.

É importante que a mulher lute a fim de atingir a igualdade no espaço público, onde impera o sistema patriarcal. O cenário mercadológico foi construído com base na cultura patriarcal, onde a mulher é definida pela natureza e sexualidade enquanto o homem é definido pelo trabalho.

Importa ainda considerar o trabalho como fundamento de construção social, concebido pelo Estado Democrático de Direito, onde a dignidade do trabalho e suas normas legais sejam cumpridas efetivamente. Por sua vez, a dignidade humana como princípio, realça a questão de deveres a serem atingidos para que a igualdade seja garantida a todos os cidadãos, como um contrato social, ou seja, caracteriza-se como um acordo estabelecido entre os membros da sociedade para que regras e regimes políticos reconheçam a autoridade, de forma igual sobre todos.

Desse modo, para que seja efetivado na prática e não apenas na teoria é preciso que o Princípio da Igualdade entre o homem e mulher permita no espaço público construir um ambiente paritário onde a mulher deixe de ser ignorada e seja reconhecida como sujeito atuante.

Frente esta realidade que permeia o âmbito laboral brasileiro, espera-se que efetivamente se reconheça a participação e o valor da mulher não apenas sob a ótica patriarcal ou apenas pelos cargos que ocupam, mas pelo que desempenha na administração pública. Desse modo, é relevante o quesito de igualdade de direitos, além de se consagrar como um importante instrumento de proteção à mulher contra sua discriminação aos cargos públicos.

Logo, torna-se de grande valia reconhecer que esse problema ultrapassa os limites das relações entre homens e mulheres, mas se incorpora como uma afronta à dignidade da pessoa humana, que por sua vez, influencia no pleno exercício da cidadania da mulher.

De acordo com o exposto, pode-se considerar que este estudo atingiu seu propósito inicial de colocar a análise da temática proposta. Cumpre ressaltar que o papel da mulher na Administração Pública é significativo pela sua singularidade e senso emotivo mais apurado, além de suas qualificações profissionais. Além disso, a liderança feminina permite agrupar seu aprendizado teórico com a prática da liderança humanizada nas relações interpessoais, em meio às exigências da globalização. 
Todavia, sua atuação ainda se esbarra com as dificuldades preconizadas pelo machismo, preconceito e ótica de fragilidade pela cultura do sexo masculino no ambiente de trabalho, o que reflete a necessidade de enfrentar desafios em relação às desigualdades no trabalho, assim como nas condições salariais, haja vista, sua ascensão dificultada no corpo organizacional, principalmente em cargos de destaque hierárquico quer seja no âmbito público ou privado.

Através de levantamentos in loco, objetivou-se através das informações coletadas, analisar a posição dos colegas masculinos frente à liderança feminina, a fim de conhecer a proposta de sua atuação com os seus colaboradores.

Os dados obtidos contribuíram para conhecer a realidade das atribuições das mulheres e o nível de aceitação em relação aos seus colaboradores na função pública.

\section{Referências}

ALVES, Edgard Antônio Lemos. Direito Administrativo. Barueri, São Paulo: Gold Editora, 2008.

CASTOR, B. V. J.; JOSÉ, H. A. A. Reforma e contra-reforma: a perversa dinâmica da administração pública brasileira. Revista de Administração Pública, Rio de Janeiro, v. 32, n. 6, 1998. nov./dez.

CASTRO, Domingos Poubel de. Auditoria e Controle interno na Administração Pública. Evolução do controle interno no Brasil: do Código de Cont. de 1992 até a criação da CGU em 2003: guia p/ atuação das auditorias e org. dos controles internos nos Estados, municípios e ONGs. 2. ed. São Paulo: Atlas, 2009.

FARHAT, A. A mulher perante o direito. São Paulo: Universitária de Direito, 2001.

FIGUEIREDO, Carlos Maurício; NÓBREGA, Marcos. Administração Pública - Direito Administrativo financeiro e gestão pública: prática, inovações e polêmicas. São Paulo: Revista dos Tribunais, 2002.

GRANJEIRO, J. Wilson. Administração Pública. 8. ed. Brasília: vest-com, GUIMARÃES, Nadya Araújo et. al. 2008 Mercados de trabalho e oportunidades: reestruturação econômica, mudança ocupacional e desigualdade na Inglaterra e no Brasil. 1. ed. Rio de Janeiro: FGV, 2002.

JUND, Sergio. Administração orçamentária e contabilidade. 3. ed. Rio de Janeiro: Elsevier, 2008.

LIMA, Carlos Alberto Nogueira de. Administração Pública para concursos. Rio de Janeiro: Elsevier, 2005.

LIMA, Diana Vaz de. Fundação da auditoria governamental e empresarial: com exercícios, questões e testes com respostas, destinados a concursos públicos. 2 ed. São Paulo: Atlas, 2009.

MATIAS-PEREIRA, J. Governança e ética na Administração Pública: estratégias de prevenção da corrupção no Brasil. Brasília: PPGA/UnB, 2007. 
MEDAUAR, Odete. Direito Administrativo Moderno. 7. ed. São Paulo: RT, p. 421, 2003.

MELLO, Celso Antônio Bandeira. 1997. Curso de Direito Administrativo. 9. ed. São Paulo: Malheiros, 1997.

O conteúdo jurídico do Princípio da Igualdade. 3. Ed. São Paulo: Malheiros, MILKOVICH, G. T.; BOUDREAU, J. W. 2000. Administração de Recursos Humanos. 1. ed. São Paulo, Atlas, 2013.

PEIXE, Blênio César Severo. Finanças públicas: controladoria governamental. 1. ed. Curitiba: Juruá, 2006.

PINHO, Ruy Rebello. Instituições de Direito Público e Privado. São Paulo: Atlas, 2002.

SALDANHA, Clezio. Introdução a Gestão Pública. São Paulo: Saraiva, 2006.

SERESUELA, Nívea Carolina de Holanda. Princípios constitucionais da Administração Pública. 8 ago. 2016. Jus Navigandi, Teresina, ano 7, n. 60, 1 nov. 2002. Disponível em:<http://jus.uol.com.br/revista/texto/3489>

SOUSA, Alfredo José de et al. O Novo Tribunal de Contas: Órgão Protetor dos Direitos Fundamentais. 2. ed. Belo Horizonte: Editora Fórum, 2004.

SPECK, Bruno. Inovação e rotina no Tribunal de Contas da União. Campinas: Fundação Konrad Adenauer, 2001.

TAKEDA, Tatiana de Oliveira. Diferenciando a Administração Direta e Indireta. 2009. Disponível em: $\langle$ jornal.jurid.com.br/old/?c=3\&m=60752\&p=53591>

VELlOSO, Raul. Papel dos Tribunais de Contas será cada vez mais importante para o País. 2011. Disponível em: < http://www.tce.ce.gov.br/ sitetce/Sessao.noticia.tce?id=480>. Acesso em: 17 set. 2016.

\section{Como citar este artigo (Formato ABNT):}

FRAGOSO, Rosa Maria Tavares. Os Efeitos da Liderança Feminina na Administração Pública, no Tribunal de Contas de Alagoas.. Id on Line Rev.Mult. Psic., 2018, vol.12, n.41, p.892-910. ISSN: 1981-1179.

Recebido: 25/07/2018.

Aceito: $27 / 07 / 2018$ 